\title{
Dental news
}

The BDJ News section accepts items that include general news, latest research and diary events that interest our readers.

Press releases or articles may be edited, and should include a colour photograph

if possible.

Please direct your correspondence to the News Editor, Kate Maynard at the BDJ, The Macmillan Building, 4 Crinan Street,

London, N1 9XW or by email to

k.maynard@nature.com

\section{PARADIGM SHIFT TOWARDS PREVENTION NEEDED FOR DENTISTRY}

On World Oral Health Day (12

September 2012) UK dental experts met with Alison Seabeck MP at a roundtable for Smiling Britain, part of a European campaign designed to raise oral healthcare on the EU agenda, to discuss the findings of the State of Oral Health in Europe Report.

'There are some pretty awful mouths out there, said Ms Seabeck, shadow minister in the Ministry of Defence, as she opened the meeting.

Professor Ken Eaton, President of the European Association of Dental Public Health and Chair of the European Platform for Better Oral Health, led the discussion on the report. Its findings show that more needs to be done to improve oral health and encourage good oral hygiene habits across Europe.

'Oral disease has shared risk factors with so many other chronic diseases and we need to develop our knowledge and the evidence base,' said Professor Eaton. 'It's a bigger team than just the dental team - we need to look at the commercial dental team as well.'

Professor Eaton pointed out that only $41 \%$ of people in the EU have all of their teeth and if these were fingers we were missing, we would worry!'

The State of Oral Health report recommends that the following actions must be considered by European decision makers: to make a commitment to improving oral health as part of EU policies by 2020 ; to address increasing oral health inequalities; to encourage good practice sharing; to improve the data and knowledge base, bridging the research gap in oral health promotion and developing the common methodologies in data collection processes; and to support the development of the dental workforce.

At present around one million people are delivering dental health care costing $€ 79$ billion a year in the $27 \mathrm{EU}$ member states.

On a UK level, Dr Nigel Carter, Chief Executive of the British Dental Health Foundation, said that the new NHS contract will reward prevention and that dentistry 'should be moving into an era of focusing on patient outcomes rather than how much drilling and filling we do'.

Echoing other speakers at the roundtable event, Dr Carter said that it is necessary for dental professionals to ally with other health care professionals for a 'whole body' approach.

Dr Carter also asserted that in the UK 'we have become complacent about what we have achieved in dental health as 50 years ago we expected to have dentures by middle age'.

A number of speakers referred to worrying statistics on mouth cancer, with an increase in cases of $48 \%$ over the last 12 years and no improvement in survival rates over the past 35-40 years.

Juliette Reeves, who has been a dental hygienist for 30 years and is also a nutritionist, said that oral health and nutrition have a fundamental relationship. Despite government campaigns, Ms Reeves said that on average only 2.8 of the recommended five portions of fruit and vegetables are consumed daily in the UK, and when combined with alcohol intake and tobacco use, it is difficult for individuals to absorb the nutritional benefits they need from food.

Ms Reeves said that more investment is needed in oral health education among schools and communities and particularly to young parents. 'MPs' help is needed in order for there to be a paradigm shift towards prevention,' said Ms Reeves, who also raised the issue of dental nurses' extended roles in applying fluoride varnish to teeth.

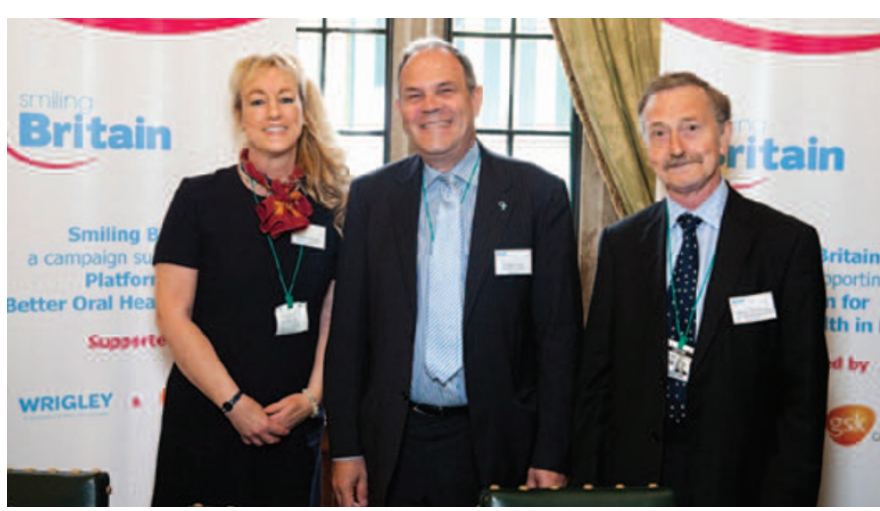

Juliette Reeves, Nigel Carter and Ken Eaton at the roundtable discussion for Smiling Britain at the House of Commons

Hazel Coey, a representative from the British Association of Dental Nurses (BADN), a society with almost 5,000 members, said that dental nurses are keen and enthusiastic to extend their roles and would embrace the opportunity to go along to health visitor sessions, nursing homes and other community groups to assist in oral health education. 'Dental nurses want to learn about caries, erosion, systemic health and nutrition, but barriers to leaving the dental practice during working hours must be removed.'

As the meeting closed, Alison Seabeck MP said that she would hold a conversation in the House of Commons based on the information presented by the speakers and given in the State of Oral Health in Europe Report. 